\title{
Generative concern; a promising health promotion component for well-being of the elderly in Galle, Sri Lanka
}

\author{
Perera $\mathbf{B}^{1}$, Fernando $\mathbf{S}^{1}$, Perera $\mathbf{R}^{2}$, Wickramarachchi $\mathbf{B}^{3}$ \\ ${ }^{\prime}$ Department of Community Medicine, Faculty of Medicine, University of Ruhuna, Galle, Sri Lanka. \\ ${ }^{2}$ Department of Psychiatry, University of Sri Jayawardenapura, Nugegoda, Sri Lanka. \\ ${ }^{3}$ Allied Health Sciences Programme, Faculty of Medicine, University of Ruhuna, Galle, Sri Lanka. \\ Correspondence: $\quad$ Prof. Bilesha Perera \\ e-mail: pperera@indiana.edu
}

\begin{abstract}
Introduction: Population of Sri Lanka is aging fast. Chronic diseases in the elderly have become a vital public health issue. Generativity, concern for teaching and nurturing the next generation, is identified as an important component of well-being of the elderly. This study assessed the generative concern in a sample of elders in Galle, and correlates of the construct.
\end{abstract}

Methods: A cross-sectional survey was conducted using an interviewer administered questionnaire in a sample of elders, aged 60 years and above in Galle. Loyola Generative Scale (LGS) and Kesslar 10 scale was used to assess generative concern and psychological stress respectively.

Results: A total of 208 elders were surveyed. The average age of the participants was 71 years (SD=7.5). The overall mean score of the LGS was $47.4(\mathrm{SD}=7.4)$. Generative concern was found to be higher among those elders whose spouse is alive $(\mathrm{p}<0.05)$, and among those who reported having had a secure income $(\mathrm{p}<0.05)$. About $39 \%$ of the participants were suffering from psychological distress. Generative concern was found not to be related to the level of psychological distress in this target group.

Discussion: The average LGS score of the elders in this sample is higher than that of elders in many countries where the figure was around 40 . Thus, a majority of the elders in this target population seems to have a greater generative concern. There is a possibility, therefore to improve health and well-being of the elderly in the area by developing and implementing intergenerational social and community development programmes.

Keywords: Elders, generative concern, psychological distress, Sri Lanka

\section{Introduction}

Aging has become a major public health issue in Sri Lanka (1-3). Increasing life expectancy at birth and declining mortality rates in the past few decades have made the population of Sri Lanka one of the fastest aging populations in the Asian region. (2). In 2001, $10 \%$ of Sri Lankans were elders (aged 60 years and over) and by the year 2030 it is estimated that about $22 \%$ of the population in the country will be elders $(2,3)$. There are many health, social and ecological implications that have occurred as a result of population aging in the country $(2,4-6)$. Elders are more susceptible to chronic diseases and deterioration of in their physical functions. They also have less access to proper health care facilities, poor income and are at risk of social isolation. Depression and cognitive impairments are common in the elderly. According to a study done in a semiurban elderly population in Sri Lanka, about $4 \%$ of the participants have dementia (7). Another study involving 100 geriatric patients in a tertiary care hospital in the country revealed that about $69 \%$ of 
them have depressive symptoms and about 56\% have some form of cognitive impairment (8).

In the past, care of the elderly is a family responsibility $(2,9)$. However, mainly due to sociocultural changes in the country over the last few decades, elderly care by the family members is becoming less prevalent in the contemporary society. Resource limitations and economic pressures do not allow the government to provide adequate support for elderly care services. In this context, population ageing has become a crucial health and development issue in the country.

Psychosocial factors, such as loneliness and low self-efficacy are vital in understanding the overall health of the elderly. Elder's feelings of loneliness have been linked to functional decline and increased risk of depression and other chronic ill-health conditions $(10,11)$. Loneliness in older adults may be partially driven by disruptions in meaningful social engagement (12-14). Generativity defined as concern of the well-being of younger generations and its related components, such as feeling socially useful or needed, are increasingly being studied and used as protective factors of successful aging $(10,14)$. Greater perceptions of generativity have been linked to better health outcomes and longevity in elders $(10,15)$. This study aimed at assessing generative concern and possible correlates of this construct in elders living in Galle.

\section{Methods}

A cross-sectional community survey was conducted in Galle using an interviewer-administered questionnaire. Two Grama-Niladari (GN) divisions (villages) were randomly selected; one urban and one rural. A household from each selected GN division was selected randomly, and then, subsequent households were identified by following a random direction from the previous household until the desired sample size was achieved. Elders living in the selected household were invited to participate in the survey. Non-response rate was $5 \%$.

The required sample size was calculated using the figure of the anticipated population mean score of the Loyola Generativity Scale (LGS) as $40(\mathrm{SD}=10)$ as indicated by a previous research (16). Thus, the minimum sample size required to estimate the mean LGS with the margin of error as 2 with $95 \%$ confidence was 96. Assuming that there is a gender difference of generative concern, the required sample size was determined as 192 (96 men and 96 women).

Loyola Generatively Scale (LGS) and Kessler Psychological Distress Scale (K 10) were used in the survey. LGS has 20 items of generative concern; concern for the care and development of the next generation and it is a reliable and valid scale to measure generative concern (17). The average LGS score is 40-41 for the older people in many countries and higher scores in the LGS indicate higher generative concern. Convergent validity of the LGS was tested with self-rated psychological health measured in a 1-5 Likert scale. Kesslar 10 is a 10 item scale to measure psychological distress of people in community settings (18). K10 has been validated in Sri Lanka and the cut off value is set as 16 (19). Higher values of K10 indicate higher level of psychological distress. Ethical approval for the research project was obtained from the Ethics Review Committee, Faculty of Medicine, University of Ruhuna, Galle, Sri Lanka.

\section{Results}

A total of 208 elders were surveyed. The majority were Sinhala (99\%) Buddhists (98\%). The demographic profile of the participants is given in Table 1.

Correlation between LGS score and self-rated mental health in the participants was positive indicating that those who have a good mental health tend to have a higher scores in their generative concern $(r=0.29, p<0.01)$. In general, it is found that generative concern is positively associated with psychological well-being $(14,15)$. Further investigations, however, are needed to validate the LGS in this target population.

The overall mean score of the LGS was 47.4 (SD = 7.4). Results indicate that generative concern, measured by LGS scale, is neither related to gender nor age. There is a slight increase in the LGS score with increasing level of education, but no significant association was found. Generative concern is found to be higher among those whose spouse is alive compared to others $(p<0.05)$, and among those who were having a secure income compared to others who did not have any regular income $(\mathrm{p}<0.05)$. 
Table 1: Demographic characteristics of the participants $(n=208)$

\begin{tabular}{|c|c|}
\hline Characteristics & $\begin{array}{c}\text { Number and percentage } \\
\text { (or mean and SD) }\end{array}$ \\
\hline \multicolumn{2}{|l|}{ Gender } \\
\hline Male & $82(39.4 \%)$ \\
\hline \multicolumn{2}{|l|}{ Level of Education } \\
\hline Primary or No Education & $43 \quad(20.7 \%)$ \\
\hline Secondary & $114(54.8 \%)$ \\
\hline Higher & $51(24.5 \%)$ \\
\hline Age & 70.6 years $(\mathrm{SD}=7.5)$ \\
\hline \multicolumn{2}{|l|}{ Living status } \\
\hline Living alone or only with the spouse & $38(18.3 \%)$ \\
\hline Living with spouse \& children/relatives & $170(81.7 \%)$ \\
\hline \multicolumn{2}{|l|}{ Occupation } \\
\hline Currently have a paid job/ pension & $80 \quad(38.5 \%)$ \\
\hline Not having/ had a regular paid job & $128(61.5 \%)$ \\
\hline \multicolumn{2}{|l|}{ Monthly income } \\
\hline Less than Rs. 10,000 & $117(56.3 \%)$ \\
\hline Rs. 10,000 - Rs. 20,000 & $51(24.5 \%)$ \\
\hline More than Rs. 20,000 & $40(19.2 \%)$ \\
\hline
\end{tabular}

Table 2: Mean scores of LGS by demographic characteristics $(n=208)$

\begin{tabular}{|c|c|c|}
\hline Characteristics & \multicolumn{2}{|c|}{$\begin{array}{c}\text { Loyola Generativity Scale } \\
\text { (Mean and SD) }\end{array}$} \\
\hline \multicolumn{3}{|l|}{ Gender } \\
\hline Male & $47.6(7.2)$ & $p=0.82$ \\
\hline Female & $47.3(7.6)$ & \\
\hline \multicolumn{3}{|l|}{ Level of Education } \\
\hline Primary or No Education & $46.3(6.3)$ & $p=0.44$ \\
\hline Secondary & $47.4(8.2)$ & \\
\hline Higher & $48.3(6.2)$ & \\
\hline \multicolumn{3}{|l|}{ Age } \\
\hline $60-69$ years & $47.1(7.1)$ & $p=0.81$ \\
\hline $70-79$ years & $47.8(7.7)$ & \\
\hline$\geq 80$ years & $47.3(7.4)$ & \\
\hline \multicolumn{3}{|l|}{ Spouse Alive / Dead } \\
\hline Spouse is alive & $48.2(6.9)$ & $p=0.03$ \\
\hline Spouse is dead & $45.9(8.1)$ & \\
\hline \multicolumn{3}{|l|}{ Occupation } \\
\hline Currently have a paid job/ pension & $49.8(6.9)$ & $p=0.01$ \\
\hline Nothaving/ had a regularly paid job & $45.9(7.3)$ & \\
\hline
\end{tabular}




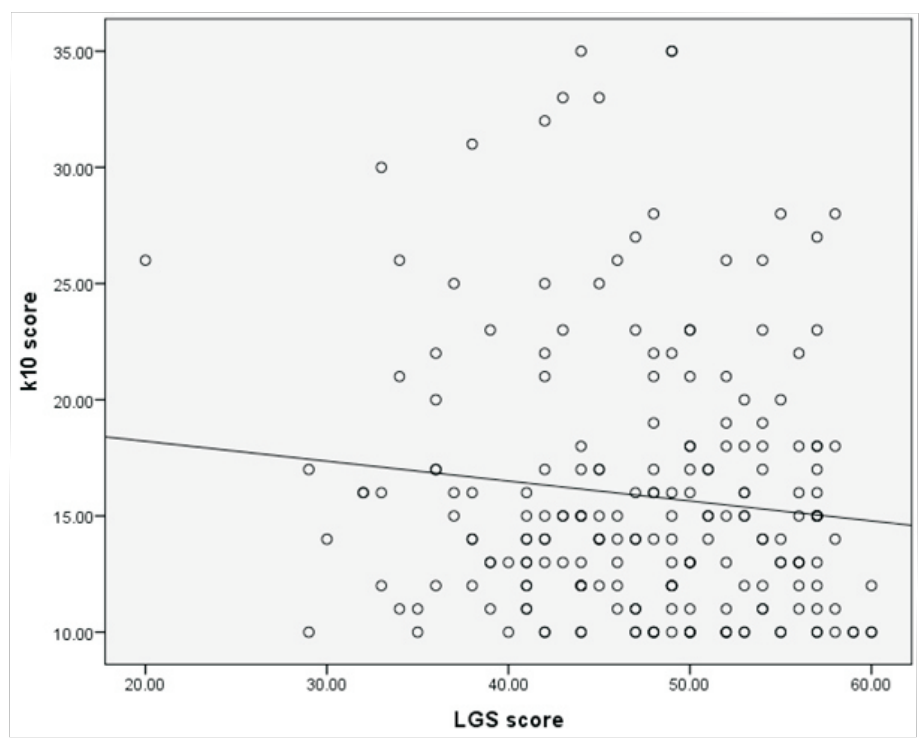

Figure 1: Scatter plot of K 10 score by LGS score

About $61 \%$ of the participants had K10 score less than 16. Generative concern is found not to be related to the level of psychological distress of the participants (Correlation coefficient $(r)=-0.11, p=$ 0.12) (Figure 1).

\section{Discussion}

Population aging is common to many developed as well as developing countries in the world today. The increases in the prevalence of chronic disease including depression and dementia in the elderly have led many governments to initiate health promotion and protection actions that prevent or at least delay adverse health consequences of the elderly $(6,20,21)$. In healthy aging, elders' desires and abilities to transfer of their knowledge and wisdom to younger generations (i.e. generativity) have been identified as an important health promotion component $(14,15)$.

In this study, a slightly higher mean score of generative concern in Sri Lankan elders, compared to such figures in elders in other countries was observed $(14,16,21)$. The findings also indicate that gender and age are not related to generative concern. Chronic diseases that become more prevalent with increasing age may bar senior elders being generative $(16,23)$. However, the observed difference of generative concern of elders in this population setting may be due to their active life style. Being an agricultural society, many elders in the country are engaged in some form of work for living. Social security benefits available for them are limited (9). As a result many elders may have opportunities for meaningful generative activities $(16,21)$. As seen in many other countries, women outlive men in Sri Lanka. This would result gender based health disparities in senior elders where women being highly subjected to suffer from chronic diseases. However, Sri Lankan older women's feeling of obligation to serve as their family's primary caregiver and active life style may stimulate them to develop generative concern and actions $(4,16)$. Factors such as less education and poverty have shown to impede elder's access to generative activities (23). Our findings support this assertion. In our study, elders whose spouse is alive and who have a secured income seem to be having a greater generative concern compared to the others. Our observations that $61 \%$ of the elders in our sample were free from moderate or severe psychological distress, and having an overall mean score of LGS as 47.4 in the total sample may indicate that the majority of elders in Galle would have a commitment and desire to nurture younger generations.

Generative concern is an important construct for successful aging. It should be noted however that generative concern and acts per se would not predict social and psychological well-being in the elderly (10), but would depend on the extent to which generative concerns and related actions are appreciated and valued by the younger generations. 
Elders' generative concern and related behavioural and demographic correlates have not been studied well in the Sri Lankan context. Thus, further research on situational and environmental factors related to generative concern, and evaluation of effectiveness of the intergenerational programs in promoting health of the elderly are warranted.

\section{References}

1. Perera B. Social support and social security issues of elders in Sri Lanka. Galle Medical Journal 2011; 16(2): 20-3.

2. Siddhisena KAP, Degraff DS. A Pace of Its Own: The Demography of Aging in Sri Lanka. Journal of Population Ageing 2009; 2: 77-99.

3. De Silva WI. Population Projections for Sri Lanka: 19912041, Institute of Policy Studies, Human Resource Development Series. Colombo: Institute of Policy Studies, 1997.

4. Samaraweera DN. Care of the elderly: a multidisciplinary approach. Journal of the Ceylon College of Physicians 2014, 45: 45-8.

5. Wanigatunge $\mathrm{C}$, Hewahetawatta U, Dissanayake S. Non Communicable Diseases and Medicines Use in Elderly Attending Public Sector Hospitals in Sri Lanka. Asian Journal of Pharmacy, Nursing and Medical Sciences October 2014; 2(5):

6. Malhotra R, Chan A, Ostbye T. Prevalence and correlates of clinically significant depressive symptoms among elderly people in Sri Lanka: findings from a national survey. International Psycho-Geriatrics 2010; 22(2): 227-36.

7. Silva HAD, Gunatilake SB, Smith AD. Prevalence of dementia in a semi-urban population in Sri Lanka: report from a regional survey. International Journal of Geriatric Psychiatry 2003; 18: 711-5.

8. Rodrigo C, Perera SM, Rajapakse AS. Cognitive impairment and symptoms of depression among geriatric patients in a tertiary care unit in Sri Lanka. Indian Journal of Psychiatry 2010; 52(3): 279-80.

9. Sandaratne N. Socioeconomic implications of ageing, in Population Association of Sri Lanka and UNFPA, 'Ageing Trends in Sri Lankan Population Problems and Prospects'. Colombo: UNFPA, 2004.

10. Cheng ST. Generativity in later life: Perceived respect from younger generations as a determinant of goal disengagement and psychological well-being. Journal of Gerontology: Psychological Sciences 2009; 64B(1): 45-54.
11. Arai H, Ouchi Y, Yokode M, Ito H, Uematsu H, Eto F, et al. Toward the realisation of a better aged society: Messages from gerontology and geriatrics. Geriatrics and Gerontology International 2012;12(1): 16-22.

12. Martin LG. The status of South Asia's growing elderly population. Journal of Cross Cultural Gerontology 1990; 5: 93-117.

13. Nugegoda DB, Balasuriya B. Health and social status of an elderly urban population in Sri Lanka. Social Science and Medicine 1995; 40(4): 437-42.

14. Rothrauff T, Cooney TM. The Role of Generativity in Psychological Well-Being: Does it differ for childless adults and Parents? Journal of Adult Development 2008; 15: $148-59$.

15. Hamby S, Thomas LA, Banyard VL, Grych J. Generative Roles: Assessing Sustained Involvement in Generativity. American Journal of Psychology and Behavioral Sciences 2015; 2(2): 24-32.

16. Maselko J, Sebranek M, Mun M H, Perera B, Ahs J, Østbye T. Contribution of Generative Leisure Activities to Cognitive Function in Elderly Sri Lankan Adults, Journal of American Geriatric Society 2014; 62: 1707-13.

17. McAdams DP, Aubin E. A theory of generativity and its assessment through self-report, behavioral acts, and narrative themes in autobiography. Journal of Personality and Social Psychiatry 1992; 62: 1003-15.

18. Kessler RC, Andrews G Colpe, et al. Short screening scales to monitor population prevalence and trends in nonspecific psychological distress. Psychological Medicine 2002; 32: 959-76.

19. Wijeratne LT, Williams SS, Rodrigo MDA, et al. Validation of the Kessler's psychological distress scale among the Sinhalese population in Sri Lanka. South Asian Journal of Psychiatry 2011;2(2): 21-5.

20. World Health Organization. The World Health Report 2005. Geneva: WHO, 2005

21. Andrews GR, Hennink MM. The circumstances and contributions of older persons in three Asian Countries: Preliminary results of a cross-national study. Asia Pacific Population Journal 1992; 7(3): 127-46.

22. Gruenewald TL, Liao DH, Seeman TE. Contributing to others, contributing to oneself: Perceptions of generativity and health in later life. The Journals of Gerontology 2012; 67(6): 960-5. (doi: 10.1093/geronb/gbs034)

23. Carlson MC, Seeman T, Fried LP. Importance of generativity for healthy aging in older women. Aging Clinical and Experimental Research 2000; 12: 132-40. 